University of Wollongong

Research Online

Faculty of Social Sciences - Papers (Archive) Faculty of Arts, Social Sciences \& Humanities

2007

Differential response: A critical examination of a secondary prevention model

Amy Conley Wright

University of Wollongong, acwright@uow.edu.au

Follow this and additional works at: https://ro.uow.edu.au/sspapers

Part of the Education Commons, and the Social and Behavioral Sciences Commons

Research Online is the open access institutional repository for the University of Wollongong. For further information contact the UOW Library: research-pubs@uow.edu.au 


\title{
Differential response: A critical examination of a secondary prevention model
}

\begin{abstract}
Whether and when to intervene and what services to offer families in crisis are critical questions in the field of child welfare. Policy makers and administrators struggle with how to target services appropriately to ensure provision to families at greatest risk while avoiding endangerment through miscalculation. This paper examines the differential (also known as alternative) response paradigm of child welfare services under which families at moderate to high risk for child maltreatment are offered preventative, strengthsbased services. The Another Road to Safety Program, an example of a differential response program utilizing home visiting as a service delivery mechanism, is critically assessed to determine support for program assumptions in the child welfare literature base. The types of intervention strategies examined include voluntary service provision, home visitation, paraprofessional service delivery, and targeting of basic and concrete needs.
\end{abstract}

\section{Keywords}

critical, model, examination, differential, secondary, prevention, response

Disciplines

Education | Social and Behavioral Sciences

\section{Publication Details}

Conley, A. (2007). Differential response: A critical examination of a secondary prevention model. Children and Youth Services Review, 29 (11), 1454-1468. 
RUNNING HEAD: Differential Response

Differential response: A critical examination of a secondary prevention model

\author{
Amy Conley \\ University of California, Berkeley \\ School of Social Welfare
}

120 Haviland Hall

Berkeley, CA 94720-7400

$510-541-0301$

a_conley@berkeley.edu

Key words: child maltreatment prevention, differential response

The author would like to express gratitude to Jill Duerr Berrick for her thoughtful critiques and to the staff from Social Services Agency of Alameda County, First Five Alameda County, and the Another Road to Safety Program for their availability and cooperation in research. 


\begin{abstract}
Whether and when to intervene and what services to offer families in crisis are critical questions in the field of child welfare. Policy makers and administrators struggle with how to target services appropriately to ensure provision to families at greatest risk while avoiding endangerment through miscalculation. This paper examines the differential (also known as alternative) response paradigm of child welfare services under which families at moderate to high risk for child maltreatment are offered preventative, strengths-based services. The Another Road to Safety Program, an example of a differential response program utilizing home visiting as a service delivery mechanism, is critically assessed to determine support for program assumptions in the child welfare literature base. The types of intervention strategies examined include voluntary service provision, home visitation, paraprofessional service delivery, and targeting of basic and concrete needs.
\end{abstract}


Child welfare is a high stakes field. With limited resources, administrators and workers have no choice but to target services to those families at greatest risk of child abuse and neglect. Yet the cost of doing nothing may be the greatest of all, if the development and well-being of children is threatened by poor parenting skills and a lack of financial resources, or in the worst case scenario, children die from parental injury or negligence. Mounting research indicates that a large proportion of children screened out at the hotline or unsubstantiated after investigation eventually come back into contact with the child welfare system (Drake et al., 2003; Wolock, et al., 2001; Inkelas \& Halfon, 1997). This is the crack in the system where all too many children and families fall, unable to access services until the severity of family problems has deepened and the family unit is under threat of dissolution. Rather than waiting until such cases are in severe crisis and warrant coercive intervention by child protective services, differential response offers an opportunity to engage families in voluntary services which address their identified risk factors.

Differential response is a fairly new approach to child welfare, more a philosophy than intervention. Under the differential response paradigm, agencies sort families by risk levels and offer services to those deemed at lower to moderate levels of risk, who under traditional child welfare services would often receive nothing. The differential response approach is characterized by voluntary provision, greater respect for families, and increased community involvement (Waldfogel, 1998a). This new way of doing business is catching the imagination of policy makers and child welfare administrators throughout the country.

In California, one differential response program called Another Road to Safety (ARS) provides an intensive home visiting program that offers families concrete services and emotional support. The program ultimately seeks to ensure child safety, improve child development, and 
strengthen family functioning. This paper critically examines aspects of the ARS program, with reference to the larger child welfare literature, and discusses the relevance of the ARS model.

\section{The case for reform}

Why do some families repeatedly come to the attention of child welfare services without receiving an intervention? From the high volume of referrals, one may infer that a large number of mandated and other reporters recognize that families need help, though their problems may not rise to the level of statutory child maltreatment. In 2004, 3 million child abuse and neglect referrals concerning 5.5 million children were made in the United States. One-third of these referrals were screened out at the hotline level, without further attention from child protective services. Of the remaining two-thirds, more than one half $(60.7 \%)$ were closed and given the disposition "unsubstantiated" because of insufficient evidence that a child was maltreated or at risk of future maltreatment (U.S. Department of Health and Human Services, 2006).

Researchers have in recent years begun to focus on the substantiated/unsubstantiated distinction, questioning whether the two populations differ significantly. The evidence is mounting that families with substantiated and unsubstantiated allegations experience similar trajectories of child maltreatment recurrence and contact with the child welfare system (Wolock et al., 2001; Drake et al., 2003; English et al., 1999; Inkleas \& Halfon, 1997), indicating that a reexamination and reformulation of the child welfare system's approach to serving families is warranted.

There are two overarching strategies advanced for Child Protective Services (CPS) reform. The first is narrowing of the CPS mandate and services. The high volume of unsubstantiated cases, according to researchers such as Douglas Besharov, represent an unnecessary intrusion into families' lives, a waste of resources, and an over-taxation of the system that prevents real 
cases of maltreatment from getting the attention they need (Besharov \& Laumann, 1996). The CPS mandate is also problematic, by placing alternating emphasis on child rescue and family preservation, when what is really needed is an individualized approach (Lowry, 1998). For these reasons, advocates of narrowing believe that reform should focus on the issues of over-inclusion, capacity, and service orientation (Waldfogel, 1998b).

The second strategy is broadening of child welfare services to create a system that truly promotes child well-being rather than intervenes only in desperate situations. As evidence of the need for broader services, researchers point to findings that initially unsubstantiated cases "recidivate" to the child welfare system at only slightly lower rates than substantiated cases, but make up the largest volume of re-reported events (Drake et al., 2003; English et al., 2002). Proponents of the broadening strategy focus on CPS problems related to under-inclusion and service delivery. The problem of under-inclusion has two components: high risk families who go unreported and low risk families whose reports are dismissed without provision of preventative services. Service delivery is also problematic; families tend to have multiple problems, yet the services are fragmented rather than holistic. To better protect children and strengthen families, this strategy proposes building partnerships in the community (Waldfogel, 1998b)

The vision that emerges from these recommendations is that of a system with services for families at different levels of risk. Currently, the system accounts for three levels of risk. In families whose children are at imminent risk of harm, the highest level, out-of-home care is provided to the children and reunification services are provided to parents. At the middle range of risk, in-home family support and preservation services are provided for children who can be maintained safely in their homes. Reports of families with perceived lowest risk are dismissed 
without services. There is a growing consensus that child welfare needs a service system for the lowest level of risk, for those families whose allegations of maltreatment do not meet the statutory definition or for which there is insufficient evidence of maltreatment, yet there is a clear need for support.

Differential response has been proposed to address the critiques of the child welfare system previously cited by narrowing the CPS mandate and the definition of abuse and neglect, and yet expanding child welfare services to lower-risk families who would not be served under the traditional system. In this model, the CPS focus would be narrowed to families at high risk. Concurrent development of an alternative services system would serve families at low to moderate risk. CPS would retain the "authoritative protective" role while relinquishing to community providers the role of family support (Waldfogel, 1998a). The CPS mandate would be narrowed in several regards: the severity of cases would be delimited, the types of abuse would be more clearly defined, the standard of proof (i.e., reasonable cause to believe) would be established, the type of caregiver (i.e., parental only) would be restricted, and the reporter characteristics (i.e., credible, known) would be specified. Cases that did not fall within the CPS purview would be referred to community services offered on a voluntary basis. Each family would be provided with a customized approach, based on their assessed level of risk and service needs. A high proportion of families would be offered community services, many of whom under the current system are turned away without any assistance (Waldfogel, 1998a).

The philosophy of differential response has caught on in a number of jurisdictions. As of 2003, more than twenty states had identifiable policies related to differential response, eleven of which had implemented services statewide (U.S. Department of Health and Human Services, 2003). In general, studies have found that child safety is preserved and that families and staff 
prefer the differential response model to traditional child welfare services (Loman \& Siegel, 2004a; Loman \& Siegel, 2004b; Virginia Department of Social Services, 2003; Center for Child and Family Policy, 2004; English et al., 2000). Reforms similar to differential response are also underway internationally, in countries including Australia, Canada, and New Zealand (Connolly, 2005).

California is a relative newcomer to this group. The California Child Welfare Redesign, a three year planning effort to re-envision child welfare services, recommended a shift to differential response (CWS Stakeholders Group, 2003). Since the conclusion of the planning process in September 2003, eleven counties in California have received funding and technical assistance to be "early implementers," and the majority of other California counties have also begun to test and implement components of differential response (Schene, Oppenheimer, \& Senderling, 2005). The Another Road to Safety program model, as this paper will argue, is worthy of further consideration as a promising approach to differential response.

\section{A critical analysis of the "Another Road to Safety" Program}

Pre-dating the California child welfare reform movement, Another Road to Safety (ARS) has since 2002 served cases screened out of the public child welfare system and diverted for community services in two Alameda County neighborhoods (with an additional neighborhood added in 2005). ARS has several unique attributes that make it worthy of study. First, ARS was implemented before the CA Child Welfare Redesign, making it the first pilot differential response program implemented in California. Second, the ARS model is unique compared with differential response programs in other states and California counties with regards to funding (through joint contributions by Alameda County First $5^{1}$ and the county social services agency),

\footnotetext{
${ }^{1}$ Each California county has a First 5 commission, dedicated to enhancing services for children under 5 and their families through use of public funds generated from a tobacco tax.
} 
staffing (by paraprofessionals), and service delivery strategy (intensive home visiting). Third and finally, because ARS is conducted by a different agency in each community, it is highly tailored to the neighborhood context. As the differential response model involves connecting families to local formal and informal resources, the ability of agencies to form connections with other service providers and neighborhood institutions is a key element of program success.

\section{The Program Model}

Screened out cases are referred to the ARS program if hotline screeners determine that the family lives within one of the targeted zip codes and has a child under the age of five and/or a pregnant mother. The program is currently undergoing expansion to serve families with children over the age of five. One of the community-based agencies receives the referral and assigns the case to a home visitor. Although parents are offered services on a voluntary basis, families who decline services are referred back to CPS for possible follow-up.

Clients consenting to services are seen weekly, during visits lasting over an hour. Each home visitor carries a caseload of no more than thirteen and, on average, only nine. This allows the staff member to devote time to creating a relationship. Within thirty days of case assignment, each home visitor conducts a variety of assessments to guide the development of the "Family Care Plan.” The family assessment covers indicators of family strengths and concerns and determines the family's ability to parent, protect children from abuse and neglect, and provide for children's special needs. Developmental and health assessments are conducted on all children in the household. Other assessments are conducted as needed, such as screens for depression and substance abuse. Jointly, the family and the home visitor develop a "Family Care Plan" which outlines goals and steps to achieve them. Both the family and the home visitor work to meet the established goals during the nine-month duration of ARS services. Services may be 
extended by an additional three months if a family continues to need support in meeting their goals. Goals fall under one of the following categories: Child safety; child growth and development; parenting; school readiness; health and wellness; building family strengths; selfsufficiency; relationships; and nutrition. These same goals are contained in ARS's accountability matrix and are the basis for program evaluation.

With the Family Care Plan to guide the intervention strategy, home visitors have an array of referrals they can provide for families. When clients have needs that cannot be met through a referral, home visitors have access to a basic needs fund. Funds may, for example, be used for food, household items, diapers, or even partial rent payments. The concept behind the basic needs fund is to prevent the crisis of an urgent and unaddressed need and the stress it induces.

Beyond concrete forms of help such as referrals and basic needs funds, the home visitor develops a therapeutic relationship that is the intervention tool with the family. They model healthy relationships and build trust by becoming a consistent and supportive presence in their client's lives. Home visitors use "teachable moments" to help parents better understand their child. This leads to improved parenting skills because lessons are concrete, not theoretical. By helping families meet realistic short-term goals, the home visitors hope to plant the seeds for deeper, more systemic changes in family functioning. ARS services are offered for a relatively brief nine-month timeframe, so the goal is to use this period to incubate changes in parenting and life skills that will promote child and family safety and well-being.

\section{Critical analysis of program components}

A process and outcome study of the ARS model is currently underway, but as yet, the assumptions and theories underlying the program remain untested. The next section will critically examine the literature base for key aspects of the ARS program model. None of the 
intervention types discussed are required for the differential response paradigm, though many have been utilized in the five states that have completed evaluations and made their findings publicly available (Loman \& Siegel, 2004a; Loman \& Siegel, 2004b; Center for Child and Family Policy, 2004; Virginia Department of Social Services, 2004; English et al., 2000). Voluntary services are characteristic of differential response services in Minnesota, Missouri, North Carolina, Virginia, and Washington State. Home visitation is used as a service delivery mechanism in North Carolina and Washington, but not in Minnesota, North Carolina, or Virginia. In these five states, paraprofessionals are generally not the providers of differential response services. CPS social workers manage cases in Minnesota, Missouri, North Carolina, and Virginia, while masters-level social workers and public health nurses with community-based organizations manage cases in Washington States. All five states report that they provide some type of services targeting basic and concrete needs, such as financial assistance and childcare referrals. Without testing, it is unknown as to whether outcomes associated with the ARS program model may be attributed to a particular intervention type, or the various interventions in combination with the differential response pathway structure.

\section{“Voluntary" child welfare services}

ARS engages its clients "voluntarily": clients may choose to accept or refuse services, though they are informed that in cases of refusal, child protective services will be notified and may choose to take action. This approach differs from the usual course of action in child welfare which involves court-mandated parent involvement in services. The child welfare system has a “dual role structure" (Pelton, 1998, p. 127); that is, agencies hold the responsibility of investigating maltreatment allegations and removing children who they consider unsafe, while simultaneously promoting family preservation and offering family support. Parents who may 
perceive concerns in their parenting are more likely to hide from a system which bestows labels of abuse and neglect rather than voluntarily seek out involvement (Pelton, 1998).

The ARS point of contact through the hotline report and the possibility of re-referral to CPS should the family refuse services throws into question whether participation can truly be considered "voluntary." While services are provided by community-based agencies rather than child protective services workers, the specter of formal child protective services involvement still remains. Few studies have examined the veracity of the "voluntary" claim in child welfare services; the studies that do exist hint that some level of coercion may still be involved. In an examination of voluntary and court-mandated foster care services in several states, Yoshikama and Emlen (1983) found that parents who voluntarily placed their children in foster care tended to do so for reasons of family conflict or parental incapacitation due to illness or financial difficulties, and that the majority reported strong influence or coercion by child welfare workers or family members in making their decision.

What are the benefits and drawbacks of offering child welfare services on a nominally voluntary rather than mandatory basis? Provision of voluntary services is viewed by the field as holding promise for greater levels of client motivation (Thomas et al., N.D.), leading to higher rates of engagement and retention in services. The field of child welfare is just beginning to examine the concept of engagement as it relates to non-voluntary clients. From a pilot test of a multidimensional measure of client engagement in non-voluntary child welfare services, Yatchmenoff (2005) reported findings which indicate the presence of four underlying factors related to the latent variable of engagement, all of which were moderately to highly correlated with each other: investment in services; expectancy in the change process; receptivity to services; working relationship between client and child welfare worker; and mistrust, an anti- 
engagement dimension. Of these five dimensions, investment in services and expectancy in the change process were so highly correlated that they were combined into a single dimension labeled "buy-in." The dimension of buy-in had the strongest predictive relationship to behavioral engagement, as measured by self-reported compliance with mandated services. Based on these preliminary findings, one may cautiously infer that community-based organizations offering voluntary services to families previously reported to the child welfare system would do best to target those clients who are receptive to change and do not need coercion to comply with services. Further, since CBOs do not have the power to remove children, the interference of mistrust in the helping process is likely minimized.

Research into voluntary family support interventions has identified a host of factors at the parent, home visitor, and community levels that influence engagement and retention of clients. Daro and her colleagues (2005) found that initial enrollment is most significantly predicted by intent to enroll, which in turn is influenced by the client's readiness to change, attitude towards seeking help, and prior service experiences. Beyond enrollment, the findings of Wagner et al. (2003) based on interviews and focus groups from a multi-site home visiting program indicate that client engagement can occur at different levels, suggesting that the construct of parent engagement is more complex than merely participation or attrition.

Since parents can opt to leave services at any time, retention is a challenge for voluntary family support programs. Daro et al. (2005) report that service participation in home visiting programs is influenced by different factors at different time periods. At the point of service engagement, the mother's perception of her infant's health risk is the most important factor. Over time, other factors assume greater importance, including the subjective experience of receiving services, the objective value of services received, the characteristics of the provider 
and the program, and the characteristics of the community. With regards to the community, families living in more chaotic communities were less likely to make use of voluntary family support for extended periods of time. This finding was replicated in a study by McGuigan et al. (2003), which found that retention for one year in a voluntary child abuse prevention program was negatively associated with community violence. Clearly, factors at the individual, agency, and community level influence engagement and retention of families in family support programs. With differential response, it will be important to gain a greater understanding of how families perceive preventive services associated with a CPS referral, their readiness to change, and how feelings of coercion may play a role in decisions to participate in services.

\section{Home Visiting}

Home visiting has a long history as a primary service delivery strategy with at-risk families. The first record of home visiting as a formal social intervention in the United States dates back to the 1880s and the Charity Organization Societies "friendly visitors" (Sweet \& Appelbaum, 2004). In modern times, home visiting has been heralded as an effective way to address or prevent a host of social problems; prominent supporters include the U.S. Advisory Board on Child Abuse and Neglect and the Canadian Task Force on Preventive Health Care (Bilukha et al., 2005). In light of the ARS focus on preventing maltreatment, this section will review research findings on home visiting program with similar goals.

In a review of outcomes research for child maltreatment prevention programs that used home visiting, Olds \& Kitzman (1993) found that of the six studies they identified with a randomized control trial methodology, none demonstrated a difference in child maltreatment reports using state CPS records. However, three studies did identify differences in rates of emergency medical services and other factors which appear to indicate a pattern of reduced parenting dysfunction. 
The researchers conclude that lack of findings using CPS records is not indicative that the programs failed to reduce child maltreatment risk; this measure may indeed be problematic due to the greater surveillance of participating families, which might skew reporting and inaccurately bias the rates of reporting among participating and non-participating families.

Another meta-analysis of home visiting identified mostly positive findings for home visitation child maltreatment prevention programs. To assess the effectiveness of home visiting as a violence prevention strategy, Bilukha et al. (2005) conducted a systematic review of home visiting programs that served children ages 0-2 years old and their families and specifically measured violence outcomes in studies with a control or comparison group. Child maltreatment subsequent to completion of services was measured directly, through reports from child protective services, parents, or others, and by proxy, through emergency room visits and hospitalizations for injury or ingestion, reported injury, and out-of-home placement. Of the 21 qualifying studies (with 26 intervention arms measuring different outcomes), 20 intervention arms measured the effect of home visitation on reports of child abuse and neglect by child protective services or by home visitors; five measured the effect on rates of injury, trauma, or ingestion of poison through medical records or mother's reports; and one measured the effect on out-of-home placement. Members of the treatment group had lower rates of child maltreatment than the comparison group in 19 of the intervention arms, with an overall median effect size of 38.9\%. In the remaining 7 intervention arms (of which 6 measured reports of child abuse and neglect and 1 measured out-of-home placement), the treatment groups had a higher rate of child maltreatment than the comparison group. As with the Olds and Kitzman review, Bilukha and his colleagues note that surveillance can bias the child maltreatment report outcome. After conducting a sensitivity analysis and adjusting results using an estimate of $50 \%$ increased 
reporting made by home visitors, the median effect size increased to $-59.7 \%$ and 3 of the intervention arms measuring reports moved from higher to lower rates of child maltreatment for the treatment group.

The ability to target child maltreatment prevention through home visitation was addressed by two meta-analyses. Sweet and Appelbaum (2004) conducted a meta-analysis of home visiting programs for families with young children. Of the 60 studies reviewed, $18.3 \%$ were of programs with the primary goal of child maltreatment prevention. The outcome of child abuse prevention was measured as three categories: actual abuse (for cases reported or suspected by service providers), potential abuse (for medical treatment that may have been associated with an incident of abuse), and parental stress (for the potential that higher stress related to parenting may result in child maltreatment). Child maltreatment "potential" was significantly reduced for participants of in programs which listed this as a primary goal, as compared to other types of home visiting programs, suggesting that it may be possible to specifically address abusive and neglectful behaviors in parents. Interventions which targeted specific populations rather than offered universal enrollment had higher effect sizes on child cognition and potential child abuse outcomes, but lower effect sizes for parenting behavior outcomes, a finding that the authors describe as "contradictory and hard-to-interpret" (p. 1447). These findings highlight the challenges of assessing outcomes of home visitation programs due to the complexity and variation of program design, a problem that is amplified when results of many studies are combined in meta-analysis.

In a similar vein, Guterman (1999) conducted a meta-analysis to investigate the connection between universal vs. targeted enrollment strategies and reported outcomes for child maltreatment prevention home visitation programs. Using both measures of maltreatment 
reports and parenting skills, the population-based programs (enrollment through broadly available services systems, such as hospitals, or enrollment using demographically-based eligibility factors, such as low socio-economic status) showed a clear trend of greater effect-size for treatment groups as compared to screening-based programs (enrollment based on screening for demographically-based and/or individual-level psychosocial risk factor). One reason for this may be that programs enrolling families based on psychosocial screens inadvertently screen-in families least likely to change from the services offered and screen-out families more likely to benefit from the intervention.

Duration of service may also contribute to client outcomes, though Olds \& Kitzman (1993) have stated their belief that quantifying number of visits and total hours of visitation is likely less important than visit content. Findings on the impact of duration are mixed. In the sub-sample of home visitation programs in their meta-analysis of programs for the promotion of family wellness and child maltreatment prevention, MacLeod \& Nelson (2000) found that effect size fluctuated by number of visits, with low effect size for programs with 1-12 visits, high effect size for programs with 13-32 visits; low again for programs with 33-50 visits; and high again for one study on a program with more than 50 visits. A meta-analysis of home visiting programs for families with young children by Sweet and Appelbaum (2004) found that the differences in child maltreatment between treatment families and controls decreased as program length increased. In an outcomes study of a child neglect home visitation prevention program, DePanfilis \& Dubowitz (2005) found no significant difference in numbers of CPS reports between clients randomly assigned to 3 months of intervention versus 9 months. Longer duration of services may not result in differences among client outcomes if the knowledge of the short duration makes staff and clients work harder to achieve goals during the program's timeframe. Staff in 
programs of short duration may also make efforts to connect families to ongoing support and services in the community that may be similar to the types of services received by clients in programs of longer duration, eliminating substantive differences between the interventions received (DePanfilis \& Dubowitz, 2005). Olds and Kitzman (1993) conclude that experimental data have yet to reveal the optimal duration or intensity of services. In short, the findings on home visiting as a strategy to prevent child maltreatment are mixed. Debates on target versus universal service allocation and program duration remain unresolved.

\section{Service delivery by paraprofessionals}

Home visiting as a service strategy relies on the formation of a helping relationship between the visitor and family (Wasik, 1993). Therefore, staffing of home visiting programs is a critical component in achieving beneficial outcomes. After repeated validation by randomized control trials, home visiting of at-risk families by public health nurses is described as a "proven practice" by the Promising Practices Network due to statistically significant treatment group effects on subsequent child injuries, environmental safety, childbearing, use of public assistance, and other health and social measures (Promising Practices Network, 2002), whereas evidence of success by paraprofessionals is more in doubt. Yet some researchers hypothesize that paraprofessionals may be the better candidates for home visiting to at-risk mothers because they may better reflect the community (Sweet \& Appelbaum, 2004, Wasik, 1993), may better relate to and empathize with clients if they have also experienced challenges as a mother (Barth, 1991; Hiatt et al., 1997), and may be able to offer the types of concrete services and problem-solving approaches that clients need (Barth, 1991). Because of these qualities, paraprofessionals may have a "reduced social distance" with their clients (Hiatt et al., 1997) and an easier time establishing trust (Wasik, 1993) compared to professionals, which may aid in relationship formation and maintenance 
(Hiatt et al., 1997). They may also be viewed as role models for the clients they serve (Wasik, 1993; Hiatt et al., 1997). On the downside, paraprofessionals may have more difficulty in achieving objectivity and setting boundaries (Wasik, 1993; Hiatt et al., 1997) and may not know how to intervene with families in ways that promote mental health and self-sufficiency (Wasik, 1993).

Researchers have noted that it is difficult to quantify the effects of paraprofessional service delivery across studies, since the term blankets a variety of individuals who differ by educational background, training received, supervision, and duties (Hiatt et al., 1997; Wasik, 1993). Paraprofessionals may be defined as having no post-high school education but plenty of life experience and familiarity with the local community (Musick \& Stott, 1990; Hiatt et al., 1997), or having an educational background ranging from no high school degree to an advanced professional degree (Wasik, 1993, Wasik \& Roberts, 1994). Regardless of formal education, researchers agree that training is a critical component to develop the necessary skills for intervention with high-risk families (Wasik, 1993; Hiatt et al., 1997). In a national survey, with 1,492 respondents (46\% response rate), Wasik \& Roberts (1994) found that of the programs employing only paraprofessional home visitors, $43.4 \%$ reported providing in-service training, with $12.4 \%$ of these programs supplementing training through written materials. Seventeen percent of programs employing only paraprofessionals reported offering no training, as compared to $47.6 \%$ of agencies employing only professionals. These findings suggest that training is perceived as particularly important for paraprofessionals. Some form of supervision was reported by $73 \%$ of all agencies (Wasik \& Roberts, 1994). The question is: with sufficient training and adequate supervision, can paraprofessionals provide similar services and achieve comparable outcomes to their professional counterparts? 
Two randomized control trials of paraprofessional home visiting programs for at-risk families found minimal impact on child maltreatment outcomes. In a study by Barth (1991), trained paraprofessionals provided six months of home visiting services to pregnant mothers with identified risk factor for child maltreatment. At the conclusion of services, no significant differences were found between the controls and participants in self-reported and officially reported child maltreatment. Barth concluded that the program's lack of success may have been due to the inabilities of paraprofessionals to deal with the needs of highly distressed families and the short duration of services to make long-term change in family functioning. Similarly, a randomized control trial of Hawaii's Healthy Start, a voluntary paraprofessionally-staffed postnatal home visiting model widely implemented throughout the United States, also found the intervention to be ineffective in reducing rates of self-reported and officially reported child maltreatment (Duggan et al., 2004). Duggan and her colleagues attributed the intervention's minimal success to issues of program implementation and conceptualization.

Comparing the effectiveness of different service providers, two randomized control trials tested differences between home visitation provided by paraprofessionals and nurses. Korfmacher and his colleagues (1999) found differences between the provider types in the areas of engagement, retention, and visit content. Compared to nurses, paraprofessionals had higher passive refusal and drop-out rates. During visits, paraprofessionals spent a larger proportion of time on environmental health and safety issues than nurses and a smaller proportion on parenting. Researchers also noted that turnover was higher among paraprofessional staff. A similar study conducted by Olds and his colleagues (2002) tested the effectiveness of nurse vs. paraprofessional home visitation on maternal and child health outcomes. Mother-child pairs served by paraprofessionals evidenced only one statistically significant effect: mothers with low 
psychological resources interacted with their children more responsively than counterparts in the group served by nurses. For most the health and social outcomes on which either visitor type produced significant effects, the effect size by paraprofessionals typically was about half that of nurses, and effect sizes rarely achieved statistical significance. Since the intervention was the same, the different outcomes are likely due to the type of service provider. Nurses may have greater legitimacy and authority with the clients they serve than paraprofessionals, particularly given health-related concerns of new parents that may help them leverage behavioral change (Olds et al., 2002).

Meta-analyses examining the effects associated with professional vs. paraprofessional home visitation staffing are mixed. Bilukha et al. (2005) found that visitation by professionals (nurses and mental health workers) was associated with lower rates of child maltreatment reporting, child injury, and out-of-home placement as compared to visitation by paraprofessionals. Program duration was also associated with effect size, with programs of a longer planned duration more likely to produce positive results in reduction of child maltreatment. In combination, visitor type and duration suggested strong effect; visitation by paraprofessionals was found to be effective only in programs of two years or longer. By contrast, Sweet and Appelbaum (2004) found that paraprofessional visitation was associated with a higher effect size than professionals and nonprofessionals for outcomes associated with possible maltreatment. Falling right in the middle, a meta-analysis by Guterman (2001) found comparable levels of engagement, retention, and child maltreatment outcomes for both nurse and paraprofessional home visitors.

Researchers do not yet fully understand the factors associated with effective paraprofessional home visitation. Implementation studies may help to explain some of the mixed findings. Hiatt 
et al. (1997) conducted an implementation study of a home visiting program originally designed for public health nurses and adjusted for paraprofessionals. Program administrators recruited women without a bachelor's degree who were mothers and older than age 18. The researchers hypothesized that due to "shared experience" and "reduced social distance" paraprofessionals would create relationships with their clients that differed from those of nurses. Some of the same qualities that uniquely suited paraprofessionals for the role of home visitor (e.g. shared experience of motherhood) created challenges for the staff in taking on this new role.

Paraprofessionals struggled with issues of gaining credibility among professional collaborators, balancing work and home life, and adjusting to a professional culture. Residing in the same neighborhoods as their clients brought benefits and drawbacks to clients and paraprofessionals; while paraprofessionals could offer an insider view, they also became hurt and defensive when professionals expressed concerns regarding the safety of the communities. When compared to nurse implementation of the intervention model, paraprofessionals were found to have spent twice as much time on environmental health (e.g. safety of living conditions) and less time on personal health issues of the mother during pregnancy. High staff turnover (50\% in two years) was a problem among paraprofessionals; retention was greater among those who had previous home visiting experience. Overall, studies which compare outcomes achieved through nurse or paraprofessional home visiting favor nurses and show negligible results for paraprofessionals.

\section{Interventions targeting basic \& concrete needs}

Home visiting is a service delivery approach, not a specific type of intervention-it may be composed of any number of services intended to achieve a variety of goals (Sweet \& Appelbaum, 2004). Most frequently, home visiting programs offer services such as: general support and encouragement to families, prenatal counseling, instruction in parenting skills, 
educational services to children, and therapy to address parents' emotional difficulties (Wasik, 1993). Help with meeting concrete and basic needs is offered less frequently, even though child welfare clients have expressed desire for services that offer material assistance (Pelton, 1982) Resolution of immediate crises can be seen as necessary before moving on to deeper issues, such as lack of support or emotional problems (Duggan et al.., 1999). Providing parents with cash assistance and vouchers can also offer psychological benefit to families involved in the child welfare system: having the freedom to use cash or vouchers as the family sees fit conveys the message that the family is valued, and that parents can be trusted to do what is in the best interests of their children (Racino, 1998).

A few studies have examined the effects of offering monetary or material assistance to families at-risk of child welfare involvement. In their review of family preservation and family support programs, Chaffin et al. (2001) found that programs designed to help families meet basic concrete needs were more effective at preventing recurrence of maltreatment than programs which offered parenting and child development-oriented services. MacLeod \& Nelson (2000) conducted a meta-analysis of service components and their outcomes related to family wellness and the prevention of child maltreatment, including provision of concrete services (e.g. emergency financial aid and housing assistance). Those home visiting programs identified as having a concrete needs component had a smaller effect size on improving family functioning than home visiting programs without such services. The authors speculate that one explanation for this finding may be that offers of concrete aid are more frequently made in programs that serve families at greater levels of crisis and poverty. Creating lasting change may be more difficult with this population than with those families who have their basic needs satisfied. 
Eamon \& Kopels (2004) reported on a handful of studies that examined outcomes for families in the "Norman" program, an effort by Illinois Department of Child and Family Services to reduce out-of-home care and facilitate reunification among clients. Direct payments of approximately \$707 each were given to 4218 families, and housing expenditures of approximately $\$ 498$ each were given to 1404 families. Families who participated in the Norman program were found to have a reduced rate of out-of-home placement, fewer days in substitute care, and a greater rate of reunification than families not receiving assistance, resulting in significant cost savings to the department.

DePanfilis \& Dubowitz (2005) conducted a study of a home-based intervention staffed by social work interns with the goal of reducing risk factors, increasing protective factors, and preventing neglect. Families from an inner city neighborhood who met risk criteria for child neglect were randomly assigned to a three-month or nine-month intervention. One component of the program was to immediately assess and address emergency needs of families within one working day of the initial research assessment. Families were assisted using a combination of referrals to community providers and direct monetary assistance from an emergency fund. Upon program completion for the whole sample, there were significant reductions in risk factors, notably in the areas of parenting and everyday stress, and improvement in protective factors, such as parental competence, from baseline to case closure and from baseline to the six-month follow-up. There was no significant difference between the groups by length of intervention.

The findings on concrete aid have generally been favorable. Cash and material assistance may make a difference in those cases where the help offered truly fits the families' needs. Indeed, help acquiring needed equipment such as a crib, or assistance in paying a bill, may be a more effective child maltreatment intervention than education on parenting skills or child 
development (Chaffin et al., 2001). However, in cases of great financial stress, a small handout or purchase of equipment may not tangibly improve the plight of families.

\section{Conclusion: How does the literature base inform the ARS Model?}

The research literature supports certain aspects of the ARS model while casting doubt on others. Researchers speculate that voluntary provision of services in child welfare may enhance client motivation and better target services to those parents ready to change, yet an often heard concern in voluntary home visitation programs is that client engagement and retention can be challenging. Findings in the literature suggest that families residing in chaotic and violent communities are harder to keep in programs, a factor important to consider in programs such as ARS that are targeted to neighborhoods with high child maltreatment rates. While services provided by the ARS program are voluntary, they are still targeted rather than universal. Screening-based studies have demonstrated smaller effect sizes than population-based studies (Guterman, 1999). Home visitation is a promising intervention strategy, though the promise is not always demonstrated (Olds \& Kitzman, 1993). The research on home visiting programs that seek to prevent maltreatment is equivocal, with meta-analyses finding no difference related to treatment (Olds \& Kitzman, 1993) as well as identifying a majority of programs with positive effects (Bilukha et al., 2005). Different program services and personnel configurations may explain these mixed findings. Home visiting services staffed by paraprofessionals have achieved mixed outcomes (Sweet \& Appelbaum, 2004; Bilukha et al., 2005; Guterman, 2001; Barth, 1991, Duggan et al., 2004), with stronger empirical findings for nurse home visiting. Provision of concrete services may address crisis situations (Duggan et al., 1999) and may provide some psychological benefits (Racino, 1998) that may help to reduce risk factors (DePanfilis \& 
Dubowitz, 2005) and ultimately prevent child welfare systems involvement (Eamon \& Kopels, 2004)

While this literature review has not found profound evidence for all of the program assumptions of the ARS model, there are many reasons to believe that this program model can achieve positive outcomes for the families it serves. It has a well-thought out theoretical base that connects service inputs to expected client outcomes. Staff members are hired with care, provided with extensive training, and immersed in support and reflective group and individual supervision. Visitation content is based on family empowerment and participation, with an eye to ensuring that basic and concrete needs are met so that families can go on to address underlying psychological and emotional problems. Family achievements are celebrated and strengths are recognized and enhanced through services. As a promising intervention, the next step is to empirically test the ARS model to determine its effectiveness and value for replication at other sites. 


\section{References}

Barth, R. P. (1991). An experimental evaluation of in-home child abuse prevention services. Child Abuse \& Neglect, 15 (363-375).

Besharov, D. J. \& Laumann, L.A. (1996). Child abuse reporting. Society, 33(4), 40-47.

Bilukha, O., Hahn, R.A., Crosby, A., Fullilove, M.T., Liberman, A., Oscicki, E., Snynder, S., Tuma, F., Corso, P., Schofield, A., \& Briss, P.A. (2005). The effectiveness of early childhood home visitation in preventing violence: A systematic review. American Journal of Preventive Medicine, 28(2S1), 11-39.

Center for Child and Family Policy (2004). Multiple Response System (MRS) evaluation report to the North Carolina Division of Social Services (NCDSS). Retrieved online March 15, 2005 from the Center for Child and Family Policy web site: http://www.pubpol.duke.edu/centers/child

Chaffin, M., Bonner, B. L., \& Hill, R. F. (2001). Family preservation and family support programs: Child maltreatment outcomes across client risk levels and program types. Child Abuse and Neglect, 25, 1269-1289.

Child Welfare Stakeholders Group (2003). CWS Redesign: The future of California's child welfare services final report. Sacramento. Retrieved online 12 March 2005 from the California child welfare services redesign web site: http://www.cwsredesign.ca.gov/res/pdf/CWSReport.pdf

Connolly, M. (2005). Differential responses in child care and protection: Innovative approaches in family-centered practice [Special Edition: Differential response in child welfare]. Protecting Children, 20 (2 \& 3), 8-20. 
Daro, D., McCurdy, K., \& Nelson, C. (2005). Engagement and retention in voluntary parent support programs: Final report. Retrieved online November 2, 2005 from the Chapin Hall Center for Children web site: http://www.chapinhall.org/article_abstract.aspx $? \operatorname{ar}=1410 \& \mathrm{~L} 2=60 \& \mathrm{~L} 3=126$

DePanfilis, D. \& Dubowitz, H. (2005). Family connections: A program for preventing child neglect. Child Maltreatment, 10(2), 108-123.

Drake, B., Jonson-Reid, M., Way, I., Chung, S. (2003). Substantiation and recidivism. Child Maltreatment, 8(4), 248-260.

Duggan, A., McFarlane, E., Fuddy, L., Burrell, L., Higman, S.M., Windham, A., \& Sia, C. (2004). Randomized trial of a statewide home visiting program: Impact in preventing child abuse and neglect. Child Abuse \& Neglect, 28, 597-622.

Duggan, A. K., McFarlane, E.C., Windham, A.M., Rohde, C.A., Salkever, D.S., Fuddy, L., Rosenberg, L.A., Buchbinder, S.B., \& Sia, C.C.J. (1999). Evaluation of Hawaii's Healthy Start Program. The Future of Children, 9(1), 66-90.

Eamon, M. K. \& Koppel, S. (2004). 'For reasons of poverty': Court challenges to child welfare practices and mandated programs. Children \& Youth Services Review, 26, 821-836.

English, D. J., Marshall, D. B., Brummel, S., \& Orme, M. (1999). Characteristics of repeated referrals to child protective services in Washington state. Child Maltreatment, 4(4), 297307.

English, D. J., Marshall, D. B., Coghlan, L., Brummel, S., \& Orme, M. (2002). Causes and consequences of the substantiation decision in Washington state child protective services. Children \& Youth Services Review, 24(11), 817-851. 
English, D. J., Wingard, T., Marshall, D., Orme, M., \& Orme, A. (2000). Alternative responses to child protective services: emerging issues and concerns. Child Abuse and Neglect, 24(3), 375-388.

Guterman, N. (1999). Enrollment strategies in early home visitation to prevent physical child abuse and neglect and the "universal versus targeted" debate: A meta-analysis of population based and screening-based programs. Child Abuse \& Neglect, 23(9), 863-890.

Guterman, N. (2001). Stopping child maltreatment before it starts: Emerging horizons in early home visitation services. Thousand Oaks: Sage Publications, Inc.

Hiatt, S. W., Sampson, D., \& Baird, D. (1997). Paraprofessional home visitation: Conceptual and pragmatic considerations. Journal of Community Psychology, 25(1), 77-93.

Inkelas, M. \& Halfon, Neal. (1997). Recidivism in child protective services. Children and Youth Services Review, 19(3), 139-161.

Korfmacher, J. (1999). Home visiting: Promise \& peril. The Signal, 7, 1-8.

Loman, L. A. \& Siegel, G.L. (2004a). Differential response in Missouri after five years. Retrieved online April 5, 2005 from the Institute of Applied Research website:: http://iarstl.org/papers/MODiffResp2004a.pdf

Loman, L.A. \& Siegel, G.L. (2004b). Minnesota alternative response evaluation final report. Retrieved online March 20, 2005 from the Institute of Applied Research website: http://iarstl.org/papers/ARFinalEvaluationReport.pdf

Lowry, M. (1998). Four commentaries: How we can better protect children from abuse and neglect. The Future of Children, 8(1), 123-126. 
MacLeod, J., \& Nelson, G. (2000). Programs for the promotion of family wellness and the prevention of child maltreatment: a meta-analytic review. Child Abuse and Neglect, 24(9), 1127-1149.

McGuigan, W. M., Katzev, A.R., \& Pratt, C.C. (2003). Multi-level determinants of retention in a home-visiting child abuse prevention program. Child Abuse \& Neglect, 27, 363-380.

Musick, J. S. \& Stott, F.M. (1990). Paraprofessionals, parenting, and child development: Understanding the problems and seeking solutions. In S. Meisels \& J. Shonkoff (Ed.), Handbook of early intervention. Cambridge, U.K.: Cambridge University Press.

Olds, D. L. \& Kitzman, H. (1993). Review of research on home visiting for pregnant women and parents of young children. The Future of Children, 3(3), 53-92.

Olds, D. L., Robinson, J., O'Brien, R., Luckey, D.W., Pettitt, L.M., Henderson, C.R., Ng, R.K., Sheff, K.L., Korfmacher, J., Hiatt, S., \& Talmi, A. (2002). Home visiting by paraprofessionals and by nurses: A randomized, controlled trial. Pediatrics, 110(3), 486496.

Pelton, L. (1982). Personalistic attributions and client perspectives in child welfare: Implications for service delivery. In T. A. Wills (Ed.), Basic processes in helping. New York: Academic Press.

Pelton, L. (1998). Four commentaries: How we can better protect children from abuse and neglect. The Future of Children, 8(1), 126-129.

Promising Practices Network (2002). Nurse family partnership. Retrieved November 20, 2005, from the Promising Practices Network web site: http://www.promisingpractices.net/program.asp?programid=16 
Racino, J. A. (1998). Innovations in family support: what are we learning? Journal of Child and Family Studies, 7(4), 433-449.

Schene, P., Oppenheimer, S., \& Senderling, C. (2005). Choosing the path less traveled: Strengthening California families through differential response Retrieved October 25, 2006 from the County Welfare Directors Association of California web site: http://www.cwda.org/downloads/DifferentialResponsePolicyBrief_FINAL.pdf

Sweet, M. A. \& Appelbaum, M.I. (2004). Is home visiting an effective strategy? A meta-analytic review of home visiting programs for families with young children. Child Development, 75(5), 1435-1456.

Thomas, K. L., Berrick, J.D., \& Koren, M.K. (N.D.). Voluntary placement and the Title IV-E Waiver: Implementing reform in a changing child welfare context. Center for Social Services Research, Unpublished document.

U.S. Department of Health and Human Services, Administration for Children and Families/Children's Bureau and Office of the Assistant Secretary for Planning and Evaluation. (2003). National study of child protective services systems and reform efforts: Review of state CPS policy. (Washington, DC: U.S. Government Printing Office).

U.S. Department of Health and Human Services, Administration for Children, Youth, and Families. (2006). Child maltreatment 2004. Washington, D.C.: U.S. Government Printing Office. Retrieved online October 10, 2006 from the U.S. Department of Health and Human Service, Administration for Children, Youth, and Families web site: http://www.acf.hhs.gov/programs/cb/pubs/cm04/index.htm 
Virginia Department of Social Services (2004). Evaluation of the differential response system. Retrieved online April 20, 2005 from the Virginia Department of Social Services web site: http://www.dss.virginia.gov/files/division/dfs/cps/reports/eval_drs_2004.pdf

Wagner, M., Spiker, D., Linn, M.I., Gerlach-Downie, S., \& Hernandez, F. (2003). Dimensions of parental engagement in home visiting programs: Exploratory study. Topics in Early Childhood Special Education, 23(4), 171-187.

Waldfogel, J. (1998a). The future of child protection: How to break the cycle of abuse and neglect. Cambridge: Harvard University Press.

Waldfogel, J. (1998b). Rethinking the paradigm for child protection. The Future of Children, 8(1), 104-119.

Wasik, B. H. (1993). Staffing issues for home visiting programs. The Future of Children, 3(3), $140-157$.

Wasik, B. H. \& Roberts, R.N. (1994). Home visitor characteristics, training, and supervision: Results of a national survey. Family Relations, 43, 336-341.

Wolock, I., Sherman, P., Feldman, L.H., \& Metzger, B. (2001). Child abuse and neglect referral patterns: A longitudinal study. Children \& Youth Services Review, 23(1), 21-47.

Yatchmenoff, D. K. (2005). Measuring client engagement from the client's perspective in nonvoluntary child protective services. Research on Social Work Practice, 15 (2), 84-96.

Yoshikama, R. T. \& Emlen, A.C. (1983). A comparison of voluntary and court-ordered foster care: Decisions services, and parental choice. Washington, D.C.: The Children's Bureau, Administration for Children, Youth, and Families, Office of Human Development Services, Department of Health and Human Services. 